\title{
Susceptibility of Some Bacterial Contaminants Recovered from Commercial Cosmetics in Jordan to Preservatives and Antibiotics
}

\author{
Qasem M Abu Shaqra ${ }^{1^{*}}$, Walid Al-Momani ${ }^{2}$ and Rania M Al-Groom ${ }^{2}$ \\ ${ }_{1}^{1}$ Jordan Medical Solutions Manufacturing Company, PO Box 5341, 13111 Zarqa, ${ }^{2}$ Department of Allied Medical Sciences, Al- \\ Zarqa University College, Al-Balqa Applied University, Jordan
}

*For correspondence: Email: qabushaqra@hotmail.com; Tel: +962 79 5009808; Fax: +962 53993077.

\begin{abstract}
Purpose: To investigate the susceptibility of bacterial contaminants recovered from cosmetics to preservatives and antibiotics.

Methods: Nine bacterial isolates recovered from various brands of commercially available cosmetics marketed in Jordan were tested for their susceptibility pattern against two paraben esters and two formaldehyde donors in addition to nine commonly used antibiotics. The biocidal effect for three preservatives was tested at $0.2 \%$ concentration while the fourth was determined at a strength of $0.3 \%$. Antibiotic sensitivity test was carried out using standard disc diffusion method.

Results: Isolates of Pseudomonas aeruginosa exhibited high resistance pattern to most of the tested preservatives and antibiotics; only one isolate was sensitive to imidazolidinyl urea while others were resistant to the 4 preservatives tested. Each of these isolates exhibited resistance to at least 5 antibiotics. Other organisms, including Escherichia coli and Staphylococcus aureus, were resistant to the class of preservatives used in the various formulations from which they were recovered and demonstrated resistance to fewer antibiotics. Coagulase-negative staphylococci were the most sensitive to both categories of antimicrobials used. One isolate was sensitive to all preservatives whereas the same isolate was resistant to only co-trimoxazole. Ciprofloxacin and norfloxacin demonstrated the highest in vitro antimicrobial effect against the contaminants investigated.

Conclusion: The bacterial contaminants of cosmetics exhibited variable cross resistance between preservatives and antibiotics. This cross resistance was species- and even strain-specific.
\end{abstract}

Keywords: Antibiotic, Bacterial contaminant, Cosmetics, Preservative, Resistance.

Tropical Journal of Pharmaceutical Research is indexed by Science Citation Index (SciSearch), Scopus, International Pharmaceutical Abstract, Chemical Abstracts, Embase, Index Copernicus, EBSCO, African Index Medicus, JournalSeek, Journal Citation Reports/Science Edition, Directory of Open Access Journals (DOAJ), African Journal Online, Bioline International, Open-J-Gate and Pharmacy Abstracts

\section{INTRODUCTION}

The microbial contamination of cosmetic products is of concern worldwide due to possible negative consequences on the health of users and on product integrity $[1,2]$. Preservatives are usually added to deal with contaminants that may inadvertently gain access into product during manufacture or normal use by consumers. One aspect of cosmetics microbiology that has not been adequately addressed is the susceptibility of contaminants of cosmetic to preservatives and antibiotics. Flores et al [3] isolated several bacterial species from contaminated cosmetics and found that many of the isolates exhibited resistance to more than one preservative category; no correlation between preservatives and antibiotic resistance was made. On the other hand, Osungunna et al [4] indicated that bacterial contaminants of cosmetics were resistant to 
many antibiotics, but again this resistance was not correlated to that of preservatives.

In a few instances, bacterial cross resistance between biocides and antibiotics were noted [5], while in others, no direct link between biocide exposure and antibiotic resistance could be established [6]. It is important to note that most of our knowledge regarding bacterial cross resistance to various antimicrobial agents was derived from studies conducted on antiseptics and disinfectants. It is probable that susceptibility pattern of cosmetic contaminants to various antimicrobials may differ due to the use of preservatives in small concentrations as compared to those used in other products.

Cosmetics are used by healthy and unhealthy individuals alike. If at the time of use, these products are contaminated with multi-drug resistant bacteria, then users particularly "patients" could be exposed to microorganisms that would be difficult to treat incase of infection development. The objective of this work was to determine the susceptibility of medically significant bacterial contaminants of commercial cosmetics to various preservatives and antibiotics in order to recommend empirical treatment for infections that might be caused by cosmetic contaminants.

\section{EXPERIMENTAL}

\section{Materials}

A total of nine bacterial isolates recovered from commercially available cosmetics by Abu Shaqra and Al-Groom [2] were chosen for this study (Table 1). The only criterion followed for the selection was the ability of the isolates to cause human infections as derived from scientific literature. Test organisms include 3 isolates of Pseudomonas aeruginosa, two of $E$. coli, two of $S$. aureus and two isolates of coagulasenegative staphylococci. The identity of isolates was confirmed using conventional tests and the diagnostic tables given by Barrow \& Feltham [7]. Tests performed for this purpose include; Gram reaction, shape, carbohydrate utilization, catalase production, oxidase test, Indole production, methyl red, Voges Proskauer, nitrate reduction, starch hydrolysis, tryptophan hydrolysis, hydrogen sulfide production, and citrate utilization.

\section{Preparation of inocula}

A cell suspension of each isolate was prepared as follows: grown colonies on Soy Bean Casein Digest (SBCD) agar for 24 hours at $35^{\circ} \mathrm{C}$ were harvested and suspended in sterile phosphate buffer $\mathrm{pH}$ 7. The absorbance of this suspension was adjusted spectrophotometrically at $625 \mathrm{~nm}$ to match that of $0.5 \mathrm{McF}$ arland standards using similar buffer. This suspension contained $2 \times 108$ CFU $\mathrm{ml}-1$ as determined by spread plate technique. Aliquots of $0.1 \mathrm{ml}$ of this preparation were used in the susceptibility testing of preservatives.

\section{Susceptibility to Preservatives}

The set of preservatives investigated were methyl paraben, propyl paraben, imidazolidinyl urea and dimethyl dimethylol hydantoin (DMDM hydantoin). The latter two compounds are classified as formaldehyde donors and are easily soluble in water whereas, the former two require heating or the addition of chelating agent for solubility. Each preservative was separately added at the required concentration to a $300 \mathrm{ml}$ of SBCD broth supplemented with $0.2 \%$ propylene glycol to aid the solubility of parabens particularly the propyl ester. The prepared lots were heated to dissolve before $20 \mathrm{ml}$ aliquots of each broth were poured into $50 \mathrm{ml}$ flasks. These flasks were then autoclaved at $121^{\circ} \mathrm{C}$ for $15 \mathrm{~min}$. The autoclaving process does not seem to affect the stability of parabens [8]. For each test organism, $0.1 \mathrm{ml}$ of each prepared bacterial suspension was used to inoculate a set of triplicate flasks (prepared above) made for the respective preservative under test. Each inoculated flask was incubated at $35^{\circ} \mathrm{C}$ for 48 hours, and then sampled by plating a loop full of its content onto SBCD agar plates. Presence or absence of bacterial growth on these plates after 24 hours of incubation at $35^{\circ} \mathrm{C}$ was taken as a criterion for establishing resistance or sensitivity of the bacterial isolate to the preservative under test.

\section{Susceptibility to antibiotics}

The antibiotic susceptibility pattern of each isolate was performed using the disc diffusion method as recommended by NCCLS standard [9]. In brief, the test suspension prepared above was used to inoculate Mueller-Hinton Agar plates using sterile cotton-tipped swabs. Antibiotic discs were placed and developed zones of inhibition were recorded after 18 hours of plate's incubation at $35{ }^{\circ} \mathrm{C}$. Interpretation of susceptibility test results was carried out according to standard sensitivity tables by the NCCLS. Isolates with zones of inhibitions that came within the intermediate reading for a particular antibiotic were considered as resistant. All media used throughout this work were the 
products of Difco- USA. Antibiotic sensitivity discs were obtained from Hi-Media, India.

\section{RESULTS}

The identified and characterized bacterial strains from the commercial cosmetics are shown in Table 1. Confirmed bacterial type, code number assigned to each, source of isolation and preservative type used as indicated on the label of each container are also given in Table 1.

The biocidal activity of five commonly used preservatives in cosmetics was established for all isolates. Table 2 shows that two isolates of $P$. aeruginosa were resistant to all preservatives tested while the third isolate was resistant to 3 out of the four. The other bacteria varied in their resistance, but it is clear that each isolate of $S$. aureus and $E$. coli was resistant to 2 preservatives. Two isolates of $E$. coli were derived from shampoo preparations with no preservative type disclosed on the labels. The isolates which exhibited least resistance to the preservatives were the coagulase- negative staphylococci (S3 and S4), the former was resistant to one preservative while the latter was resistant to none.

Antibiotic susceptibility pattern of the nine isolates is shown in Table 3 . It is evident that each isolate of $P$. aeruginosa was more resistant to the nine antibiotics employed than any other isolate tested. The two isolates of coagulasenegative staphylococci (S3 \& S4) as well as $E$. coli (E2) were the most susceptible as they demonstrated resistance to 3 or less antibiotics. The most effective antibiotics were ciprofloxacin and norfloxacin then followed by ceftriaxone. The highest rate of resistance among the isolates studied was exhibited against Amoxicillin, followed by tetracycline and then gentamycin; these antibiotics were ineffective against at least 6 of the isolates (Table 3).

Table 1: Cosmetic sources of bacterial isolates and the preservatives declared on the label

\begin{tabular}{lcll}
\hline Bacterial isolate & Code no. & Source of isolation & Preservative \\
\hline P. aeruginosa & P1 & Body lotion & Parabens \\
P. aeruginosa & P2 & Hair repair emulsion & Parabens \\
P. aeruginosa & P3 & Shampoo & DMDM hydantoin \\
E. coli & E1 & Shampoo & NI+ \\
E. coli & E2 & Shampoo & NI+ \\
S. aureus & S1 & Hair conditioner & Parabens \\
S. aureus & S2 & Hair styling gel & Parabens \\
Staphylococcus sp* & S3 & Hair groom & Parabens \\
Staphylococcus sp* & S4 & Hand cream & Parabens \\
\hline \multicolumn{2}{c}{+ Not indicated; ${ }^{*}$ Coagulase negative staphylococci } &
\end{tabular}

Table 2: Biocidal effect of specific concentrations of preservatives on bacterial contaminants of cosmetic products

\begin{tabular}{lcccccccccc}
\hline Preservative & $\begin{array}{c}\text { Conc } \\
\text { (\%w/v) }\end{array}$ & \multicolumn{1}{c}{ Biocidal effect of preservatives against contaminants } \\
\cline { 3 - 12 } & & $\boldsymbol{P 1}$ & $\boldsymbol{P 2}$ & $\boldsymbol{P 3}$ & $\boldsymbol{E 1}$ & $\mathbf{E 2}$ & $\mathbf{S 1}$ & S2 & S3 & S4 \\
\hline Methyl paraben & 0.2 & $\mathrm{R}$ & $\mathrm{R}$ & $\mathrm{R}$ & $\mathrm{S}$ & $\mathrm{S}$ & $\mathrm{S}$ & $\mathrm{R}$ & $\mathrm{S}$ & $\mathrm{S}$ \\
Propyl paraben & 0.2 & $\mathrm{R}$ & $\mathrm{R}$ & $\mathrm{R}$ & $\mathrm{S}$ & $\mathrm{S}$ & $\mathrm{S}$ & $\mathrm{R}$ & $\mathrm{R}$ & $\mathrm{S}$ \\
Imidazolidinyl urea & 0.3 & $\mathrm{R}$ & $\mathrm{S}$ & $\mathrm{R}$ & $\mathrm{R}$ & $\mathrm{R}$ & $\mathrm{R}$ & $\mathrm{S}$ & $\mathrm{S}$ & $\mathrm{S}$ \\
DMDM hydantoin & 0.2 & $\mathrm{~S}$ & $\mathrm{R}$ & $\mathrm{R}$ & $\mathrm{R}$ & $\mathrm{R}$ & $\mathrm{R}$ & $\mathrm{S}$ & $\mathrm{S}$ & $\mathrm{S}$ \\
\hline *
\end{tabular}

Table 3: Antibiotic sensitivity pattern of various antibiotics against their isolates

\begin{tabular}{lcccccccccc}
\hline Antibiotic & Conc (ug) $^{*}$ & \multicolumn{10}{c}{ Bacterial isolates } \\
\cline { 3 - 10 } & & P1 & P2 & $\boldsymbol{P 3}$ & E1 & E2 & S1 & S2 & S3 & S4 \\
\hline Amoxacillin & 25 & $\mathrm{R}$ & $\mathrm{R}$ & $\mathrm{R}$ & $\mathrm{R}$ & $\mathrm{R}$ & $\mathrm{R}$ & $\mathrm{S}$ & $\mathrm{R}$ & $\mathrm{S}$ \\
Tetracycline & 30 & $\mathrm{R}$ & $\mathrm{R}$ & $\mathrm{R}$ & $\mathrm{S}$ & $\mathrm{R}$ & $\mathrm{S}$ & $\mathrm{R}$ & $\mathrm{R}$ & $\mathrm{S}$ \\
Cotrimoxazol & 25 & $\mathrm{R}$ & $\mathrm{R}$ & $\mathrm{R}$ & $\mathrm{R}$ & $\mathrm{S}$ & $\mathrm{S}$ & $\mathrm{S}$ & $\mathrm{S}$ & $\mathrm{R}$ \\
Ciprofloxacin & 5 & $\mathrm{~S}$ & $\mathrm{~S}$ & $\mathrm{~S}$ & $\mathrm{~S}$ & $\mathrm{~S}$ & $\mathrm{R}$ & $\mathrm{S}$ & $\mathrm{S}$ & $\mathrm{S}$ \\
Gentamycin & 10 & $\mathrm{~S}$ & $\mathrm{R}$ & $\mathrm{R}$ & $\mathrm{R}$ & $\mathrm{R}$ & $\mathrm{R}$ & $\mathrm{R}$ & $\mathrm{S}$ & $\mathrm{S}$ \\
Norfloxacin & 10 & $\mathrm{R}$ & $\mathrm{S}$ & $\mathrm{S}$ & $\mathrm{S}$ & $\mathrm{S}$ & $\mathrm{S}$ & $\mathrm{S}$ & $\mathrm{S}$ & $\mathrm{S}$ \\
Nalidixic acid & 30 & $\mathrm{R}$ & $\mathrm{S}$ & $\mathrm{R}$ & $\mathrm{S}$ & $\mathrm{S}$ & $\mathrm{R}$ & $\mathrm{S}$ & $\mathrm{S}$ & $\mathrm{S}$ \\
Ceftriaxone & 30 & $\mathrm{R}$ & $\mathrm{S}$ & $\mathrm{R}$ & $\mathrm{S}$ & $\mathrm{S}$ & $\mathrm{S}$ & $\mathrm{S}$ & $\mathrm{S}$ & $\mathrm{S}$ \\
Tobramycin & 10 & $\mathrm{R}$ & $\mathrm{R}$ & $\mathrm{S}$ & $\mathrm{R}$ & $\mathrm{S}$ & $\mathrm{R}$ & $\mathrm{R}$ & $\mathrm{S}$ & $\mathrm{S}$ \\
\hline * Concentration of antibiotic discs & & & & & & & & &
\end{tabular}




\section{DISCUSSION}

This investigation was performed to find out whether the wide spread use of preservatives in cosmetic preparations could have contributed in the emergence of antibiotic-resistant bacteria. Isolates tested in this investigation were recovered from a variety of skin and hair cosmetics at the point of sale. Therefore, these contaminants must have been introduced into these products during the manufacturing process. Ferrarese et al [10] demonstrated that bacteria recovered from the environment of a cosmetic factory were resistant to several preservatives. This resistance was comparable to that exhibited by our contaminants. It is clear from this table that all isolates of $P$. aeruginosa were resistant to the preservatives more than the other isolates. This observation is consistent with the generally accepted literature.

Most of the cosmetic brands employed in the investigation disclosed the use of parabens and did not specify the type of ester(s) used. It is evident from the results presented that isolates of $P$. aeruginosa were resistant to methyl and propyl paraben. This may suggest that either both compounds were employed as preservatives or that the isolated strains exhibited cross resistance against the two paraben compounds; this would be probably the case if a single preservative was used. If this assumption is true, then it is likely that resistance to one paraben ester could have conferred resistance to the other. Bacterial cross resistance between various paraben esters has long been acknowledged [5,11,].

Each isolate was resistant to the preservative used in the product from which it was isolated. The two isolates of $E$. coli were derived from two shampoo preparations with unknown preservative type used in formulation. These strains were resistant to both Imidazolidinyl urea and DMDM hydantoin. If these products were preserved with either of these compounds, then it is evident that cross resistance between the two formaldehyde donors had occurred; this cross resistance is already known to occur [12].

Chapman [13] tested a collection of bacterial isolates resistant to a variety of preservatives and found that all isolates were resistant to preservatives other than the selecting compound. The same author indicated that pattern of cross resistance to preservatives varied from one organism to another. These findings are not too different from ours, as the findings of the present study suggest that resistance to preservatives varied from one isolate to another and that several isolates exhibited resistance to preservatives other than the presumed selecting one. It is worth noting that one $S$. aureus was resistant to a formaldehyde donor while the other was resistant to both paraben esters. Thus, it is valid to conclude that preservative resistance among cosmetic contaminants is strain-specific and not even species-specific.

The observation that coagulase-negative staphylococci (S4) was susceptible to all preservatives is rather peculiar as one would have expected this contaminant to be at least resistant to preservative (s) used in the relevant formulation. Abu Shaqra and Al- Groom [2] indicated that coagulase-negative staphylococci and Micrococcus species were recovered only from cosmetics that were heavily contaminated with mixed cultures. The same authors suggested that survival and growth of these organisms were probably contingent on the presence of other microorganisms. In separate experiments (unpublished data) we found when a pure culture of coagulase- negative staphylococci was inoculated into a partially preserved hand lotion, all organisms were killed in few hours but when they were inoculated as part of a mixed culture they were found to survive. This indicates that a form of synergistic interaction takes place between the various contaminants of cosmetics and this might explain why S4 isolate was sensitive to all preservatives.

Antibiotic sensitivity testing indicated that isolates of $P$. aeruginosa were the most resistant and the high resistance is in agreement with most published data particularly those reported in medical practice [14,15]. The susceptibility pattern of the coagulase- negative staphylococci reported in this work is remarkably different than those determined for similar isolates incriminated as aetiologic agents of nosocomial infections [16]. Lambert et al [17] indicated that the selective pressure of antibiotic usage in hospitals accounts for the increase in antibiotic preservatives resistance. The same author found that this resistance was not quite marked among environmental and industrial isolates. This could be the reason for the variation in the antibiotic susceptibility given in table 3 as all of our isolates were primarily derived from industrial origin and probably had no contact with antibiotics.

The only work that tested cosmetic contaminants for their antibiotic sensitivity was published by Osungunna et al [4]. These results presented by these authors are in agreement with ours in regard to the multi-drug resistance exhibited by the 3 isolates of $P$. aeruginosa but differed in case of the Staphylococcus aureus. In fact, 100 $\%$ of the isolates of Osungunna et al [4] were 
resistant to $54.5 \%$ of the antibiotics used. In contrast to our findings where multidrug resistance was demonstrated in $77.8 \%$ of the isolates, $55.5 \%$ of our isolates were resistant to fewer antibiotics.

It is evident from this communication that a certain degree of correlation between preservatives and antibiotics resistance does exist among cosmetic contaminants, this was deduced from the resistance of two $P$. aeruginosa isolates to all preservatives and to at least 6 of the antibiotics tested. On the other hand, isolate S4 was sensitive to all preservatives and to 8 of 9 antibiotics employed in the experiment. These observations indicated that if infection develops due to the use of contaminated cosmetics, empirical treatment may not be very useful. In this situation, effective treatment should be based on laboratory determination of the antibiotic sensitivity of the etiologic agent.

\section{Limitation of the study}

The phenomenon of cross resistance between various antimicrobial agents was extensively investigated between disinfectants and antibiotics but results, as yet, are not conclusive. Cross resistance is seldom studied in bacterial contaminants of cosmetics. In the present work, several important issues were addressed but the use of 9 cosmetic contaminants might not have been enough for the derivation of comprehensive conclusions. Future research in this field should consider the use of a larger number of isolates.

\section{CONCLUSION}

Cross resistance among cosmetic contaminants occurs particularly within members of the same preservative category and to a lower extent among unrelated compounds. Preservative pressure in these products induced the development of antibiotic resistant bacteria but this resistance varies from one isolate to another. The fluoroquinolones, ciprofloxacin and norfloxacin, may be used for the empiric treatment of infections attributed to the use of contaminated cosmetics pending availability of laboratory test results.

\section{REFERENCES}

1. Alvarez-Lerma F, Maull E, Terradas R, Segura C, Planells I, Coll $P$, Knobel $H$, Vazquez A. Moisturizing body milk as a reservoir of Burkholderia cepacia: outbreak of nosocomial infection in a multidisciplinary intensive care unit. Critical Care 2008; 12: R10.

2. Abu Shaqra QM, Al-Groom RM. Microbiological quality of hair and skin care cosmetics manufactured in Jordan. Int Biodeter Biodegrad 2012; 69: 69-72.

3. Flores $M$, Morillo $M$, Crespo $M L$. Deterioration of raw materials and cosmetic products by preservative resistant micro-organisms. Int Biodeterior Biodegrad 1997; 40: 157- 606.

4. Osungunna MO, Oluremi BB Adetuyi A. Bacteriological and antibiotic sensitivity patterns of bacterial isolates from creams and lotions hawked in Sagamu, Ogun State. Pakistan J Nutri 2010; 9: 773-775

5. Braoudaki M, Hilton AC. Adaptive resistance to biocides in Salmonella enterica and Escherichia coli 0157 and cross-resistance to antimicrobial agents. $J$ Clin Microbiol 2004; 42: 73-78.

6. Cole EC, Addison RM, Rubino JR, Leese KE, Dulaney PD, Newell MS, Wilkins J, Gaber DJ, Wineinger T, Criger $D A$. Investigation of antibiotic and antibacterial agent cross-resistance in target bacteria from homes of antibacterial product users and non users. J Appl Microbiol 2003; 95: 664-676.

7. Barrow, G, Feltham, R. Cowan and steels manual for the identification of medical bacteria, 3rd ed. Cambridge: Cambridge University Press; 1993,

8. Tran TT, Hurley FJ, Shurbaji, Koopman LB. Adequacy of cosmetic preservation: Chemical analysis, microbial challenge and in-use testing, Int J Cosmet Sci 1994; 16: 61-76.

9. NCCLS. Performance Standards for Antimicrobial Disk Susceptibility Tests, 6 th ed. Approved Standards. Document M2- A6. Wayne, PA: NCCLS 1997.

10. Ferrarese $L$, paglia $R$ Ghirardini $A$. Bacterial resistance in cosmetics industrial plant: connected problems and their solution Ann Microbiol 2003; 53: 477-490.

11. Russell $A D$ Furr JR. Susceptibility of porin- and lipopolysaccharide-deficient mutants of Escherichia coli to a homologous series of esters of $p$ hydroxybenzoic acid. Int J Pharmaceut 1985; 27: 163-173

12. Chapman JS. Antimicrobial mechanisms of selected preservatives and the bacterial response. In: Geis PA., editor. Cosmetic microbiology: A practical approach. 2nd ed. New York: Taylor \& Francis Group, 2006; pp 181-192.

13. Chapman JS. Characterizing bacterial resistance to preservatives and disinfectants. Int Biodeter Biodegrad 1998; 41: 241-245.

14. van Eldere J. Multicentre surveillance of Pseudomonas aeruginosa susceptibility patterns in nosocomial infections. J Antimicrob Chemother 2003; 51:347352.

15. El Zowalaty ME. Alarming trend of antibiotic resistance in Pseudomonas aeruginosa isolates. J Pure Appl Microbiol 2011; 5: 511-516.

16. Singhal R, Dhawan S, Mohanty S, Sood S, Dhawan B, Das B, Kapil A. Species distribution and antimicrobial susceptibility of coagulase negative staphylococci in a tertiary care hospital; Indian J Med Res 2006; 123: 569-570

17. Lambert RJW, Joynson JA Forbes B. The relationships and susceptibilities of some Industrial, Laboratory and Clinical isolates of Pseudomonas aeruginosa to some antibiotics and biocides. J Appl Microbiol 2001; 91: 972-984. 